\title{
Filosofía después de Auschwitz en Th. Adorno: metafísica negativa*
}

\author{
Philosophy after Auschwitz in Th. Adorno: \\ negative metaphysics
}

\author{
Por: Arlex Berrío Peña \\ G.I. Studia \\ Universidad del Norte \\ Cartagena, Colombia \\ E-mail: arlex_berrio@hotmail.com \\ ORCID: 0000-0002-9841-5399
}

Fecha de recepción: 20 de marzo de 2018

Fecha de aprobación: 6 de septiembre de 2018

Doi: 10.17533/udea.ef.n59a10

Resumen. Este artículo parte de las reflexiones de Adorno sobre una nueva idea de filosofía desarrollada en Dialéctica Negativa, concretamente en el apartado "Meditaciones sobre la metafisica". En este pasaje, el autor expone una crítica de las categorías de la metafisica tradicional que sirven de fundamento para la propuesta filosófica de la Ilustración, tanto en Kant como en Hegel. La reflexión crítica considera que la filosofía ha sido cómplice de la barbarie en la historia. De este modo, Auschwitz como nueva categoría de análisis y expresión metafórica de la irracionalidad y barbarie que destruye lo humano y el medio natural, permite hacer el ejercicio reflexivo. Por esta razón, para Adorno es urgente hacer un replanteamiento de la filosofia después de Auschwitz para evitar que nuevas formas de terror se repitan. Una nueva idea de metafisica con un horizonte de comprensión, intervención, transformación y resignificación. En suma, se propone una metafísica negativa que se direccione hacia lo desechado por la racionalidad tradicional.

Palabra Claves: barbarie, filosofia, Auschwitz, metafísica, dialéctica negativa

Abstract. This article is based on Adorno's reflections on a new idea of philosophy developed in Negative Dialectics, specifically in the section "Meditations on Metaphysics". In this passage, the author develops a critique of the categories of traditional metaphysics that serve as the basis for the

* Este artículo es parte de la investigación: "La superación de la barbarie, la emancipación del sujeto y la autorreflexión crítica: fines del proyecto educativo en Theodor Adorno", para alcanzar el título de maestría realizado por el autor en la Universidad del Norte (Barranquilla-2016).

\section{Cómo citar este artículo:}

MLA: Berrio Peña, Arlex. "Filosofía después de Auschwitz en Th. Adorno: metafísica negativa". Estudios de filosofia 59 (2019): 213-232.

APA: Berrio Peña, A. (2019). Filosofía después de Auschwitz en Th. Adorno: metafísica negativa. Estudios de filosofia, $59,213-232$.

Chicago: Arlex Berrio Peña. "Filosofía después de Auschwitz en Th. Adorno: metafísica negativa". Estudios de filosofia n. ${ }^{\circ} 59$ (2019): 213-232. 
philosophical proposal of the Enlightenment, both in Kant and Hegel. Adorno considers that philosophy has been an accomplice of barbarism in history. In this way, Auschwitz as a new category of analysis and metaphorical expression of irrationality and barbarism that destroys the human and the natural environment, allows the exercise of reflection. For this reason, for Adorno it is urgent to rethink philosophy after Auschwitz to prevent new forms of terror from repeating themselves. A new idea of metaphysics with a horizon of understanding, intervention, transformation and resignification is put forward. In short, a negative metaphysics that is directed towards what has been discarded by the traditional rationality.

Key Words: barbarism, philosophy, Auschwitz, metaphysics, negative dialectics

\section{Introducción}

La propuesta de una nueva idea de filosofía después de Auschwitz, Adorno la desarrolla en Dialéctica Negativa. Según su interpretación, lo más importante antes de explicar cualquier concepción o interpretación filosófica de la realidad, es responder en qué consiste eso que llamamos filosofía. Si es posible aún hoy en día o si, por el contrario, ha fracasado al no haber realizado el objetivo de transformación de la praxis que se había propuesto ( $C f$. Barahona, 2006). Por esta razón, el apartado Meditaciones sobre la metafísica reflexiona sobre las contradicciones de las categorías de la metafísica tradicional, desde una 'lógica de la desintegración', para, alcanzando la liquidación de toda forma de idealismo, conseguir que estas categorías sean 'refuncionalizadas' (Cf. Buck-Morss, 1981). Al respecto, Adorno (1975) en el prólogo de la obra lo expresa en los siguientes términos: "el último capítulo gira y tantea alrededor de las preguntas metafísicas, en el sentido de que la autorreflexión crítica hace a su vez revoluciones a la revolución copernicana" (p. 9). Por esta razón, Meditaciones sobre la metafísica nombra las nuevas categorías sobre las que podrá tener posibilidad la metafísica después de Auschwitz a partir de la construcción de una nueva idea de racionalidad que supera lo meramente conceptual. ${ }^{1}$

En las primeras páginas de Dialéctica Negativa, Adorno (1975) pregunta: “¿Es aún posible la filosofía?” (p. 11), ${ }^{2}$ y al final de la obra igualmente expresa: “Un

1 Cho (2009) reconoce que en Meditaciones sobre la metafisica Adorno construye la novedad de un proyecto metafísico, moral y educativo. No es posible comprender la propuesta del frankfurtiano sin atender, de manera reflexiva, este apartado.

2 Según Peleato (2007) hay que diferenciar los distintos usos que Adorno hace de la filosofía en sus textos: primero, como lógica que persiste en la dimensión afirmativa del pensamiento, obviando aquellos contenidos que no se adecuan al principio de identidad; segundo, como dialéctica afirmativa, por cuanto se supera el esquema identitario de la lógica tradicional, ya que se incluye el elemento negativo en su 
pensamiento de tal índole es solidario con la metafísica en el mismo momento en que esta se viene abajo" (p. 405). La discusión se desarrolla contra sistemas idealistas (Hegel, Kant), positivistas; y la necesidad de reconstruir la idea de filosofía. La impronta de este ejercicio es su carácter crítico, dialéctico y negativo que permite pensar en la formulación de una nueva forma de racionalidad que, en el espectro de una teoría "crítica", rechace la afirmación de lo positivamente existente $(C f$. Barahona, 2006, p. 204).

No puede olvidarse el papel que juega Auschwitz, como categoría de comprensión en Adorno, para pensar y cuestionar el problema de la metafísica tradicional. La explicación radica en que Auschwitz, como evento fáctico e histórico, según Adorno, enfrenta las categorías de la razón de un modo que afecta sus fundamentos, sus pretensiones y su capacidad de proyección. Se trata de una negatividad que no puede ser superada e integrada, que no deja avanzar la historia, ni se resuelve en un resultado, ni permite seguir comprendiendo la racionalidad y sus categorías de la misma manera (Cf. Zamora, 2010, p. 175).

Aun cuando Adorno ha reflexionado sobre las preguntas por la metafísica, pensar que aún es posible la filosofía implica una alteración cualitativa en las categorías que se conservan en sí mismas (Cf. Adorno, 1975, p. 8). Por ello, la reflexión filosófica está marcada por un antes y un después de Auschwitz, lo cual exige a la filosofía que asuma una tarea autocrítica radical, en la que se investiguen las complejidades epistemológicas, éticas, políticas, históricas y culturales, con el propósito de generar mecanismos de resistencia frente a la barbarie, lo cual no es posible en el marco de una reflexión exclusivamente especulativa ( $C f$. Zamora, 2010, p. 206) y sí en una que esté determinada por la diferencia entre el 'antes' y ‘después' de Auschwitz, como se hace en esta investigación.

Con estas ideas, se ha decidido desarrollar la reflexión de la siguiente manera: primero, se analizan las condiciones que exigen al ejercicio reflexivo de la filosofía una nueva forma de comprender la realidad. Después de Auschwitz, la racionalidad entiende la experiencia del sujeto y el materialismo como escenarios indispensables para una nueva forma de pensar la razón. Segundo, se parte de los principales conceptos del sistema de pensamiento de Hegel (Dialéctica, Identidad,

proceder, lo cual la convierte en una simple descripción fáctica legitimadora de lo existente; tercero, la filosofía como dialéctica negativa, pues allí aparece la constatación de que la crítica implica la incorporación de un 'darse cuenta' del elemento negativo de la realidad (Cf. p. 88). 
Historia, Idealismo) para comprender la renovación de las mismas en sentido crítico-negativo, según la novedad del proyecto de Adorno. Por último, se analiza el diálogo que Adorno hace con Kant para saber si aún es posible la metafísica. Para el autor de la Dialéctica Negativa, Kant hizo un aporte significativo a la forma de interpretar la relación epistemológica entre sujeto-objeto, e igualmente la manera como se puede comprender la metafísica. Sin embargo, Adorno considera que la orientación de Kant sobre la metafísica debe ubicarse en un escenario donde sea posible entender al hombre por fuera de su condición como sujeto absoluto y la realidad más allá de categorías de aprehensión para el conocimiento.

\title{
Filosofía Después de Auschwitz
}

En las primeras páginas de Dialéctica Negativa se afirma:

\begin{abstract}
Kant declaró haber superado la filosofía de escuela con una concepción universal de la filosofía. Ahora la filosofía ha sido obligada a retroceder a su concepción de escuela, y hace el ridículo siempre que pretende confundir a ésta con aquella concepción universal. Hegel incluía la filosofía en la doctrina del Espíritu Absoluto; pero sabía que simplemente era un factor de la realidad. A partir de aquí se desarrollaría después su limitación y desproporción con la realidad, tanto más cuando olvidó más a fondo aquel límite y rechazó como algo extraño toda reflexión sobre su lugar propio en una totalidad... Sólo una filosofía que se despoje de tal ingenuidad vale de algún modo la pena de seguir siendo pensada (Adorno, 1975 , p. 12).
\end{abstract}

Para Adorno, el problema de la legitimidad y validez de la filosofía predominó tradicionalmente en la tarea de interpretar el mundo, sin conceder lugar a la reflexión que se orienta hacia la intervención y la transformación de un estado de cosas preestablecidas, pues se ha enfocado exclusivamente a un trabajo reflexivo-teórico (Cf. Adorno, 1975, p. 11). Por ello, en Dialéctica Negativa manifiesta: "Tal vez la interpretación que prometió una transición a la praxis fue insuficiente" (p. 11). Sin embargo, a pesar de esta situación, Adorno cree que "La filosofía, que antaño pareció superada, sigue viva" (p. 11), porque su promesa de reconciliación y transformación del mundo no ha concluido todavía ( $C f$. Teimil, 2007, p. 80).

Para el pensador frankfurniano no se trata de buscar una nueva teoría alternativa, sino indagar en el interior de la metafísica y sus categorías para demostrar a través de ellas y en su crítica el momento en el que se tornan falsas y conquistar su revocación y resignificación. Significa cuestionar los contenidos gnoseológicos de la tradición filosófica para ponerlos al descubierto como categorías 
de dominio (Cf. Escuela, 2007, p. 89). Por esta razón, Adorno (1975) manifiesta: "Desde que la filosofía faltó a su promesa de ser idéntica con la realidad o estar inmediatamente en vísperas de su producción, se encuentra obligada a criticarse sin consideraciones" (p. 11). Desde este horizonte, Honneth (2009) afirma:

\footnotetext{
... Adorno cree que desde la caída de Hegel, sellada por Marx, el único camino que le queda abierto a la filosofía es la autocrítica de sus presupuestos previos; no la naturalización posmetafísica de Hegel o de Kant, no la reconstrucción de un concepto modesto de racionalidad, sino descubrir el límite que tiene por principio todo esfuerzo conceptual es lo único que Adorno todavía considera posible en la filosofía tras el fracaso del idealismo de la razón (p. 89).
}

Para Adorno la tarea filosófica, después de Auschwitz, no pretende corregir las falencias planteadas por las corrientes tradicionales, sino mostrar las dificultades que se derivan de los principios que se han empleado como fundamento del trabajo epistemológico; $\mathrm{y}$, a partir de ello, establecer nuevos principios que permitan pensar la metafísica y su ejercicio de manera diferente. Sin embargo, eso solo será posible en la medida en que el ejercicio reflexivo supere el distanciamiento entre la realidad y la teoría. En este orden de ideas, la expresión del fracaso de la filosofía a partir de Auschwitz es la posibilidad para comenzar a transformar la reflexión en crítica, y así buscar nuevas formas para el pensamiento filosófico.

Para el autor de la Dialéctica Negativa, la filosofía debe exponerse a la situación histórica, porque considera que las condiciones en las que se encuentra la vida son los escenarios que deben apropiarse una nueva consideración para la metafísica ( $C f$. Adorno, 1975, p. 16). De este modo, la filosofía comienza a enraizarse en lo que era imposible de ser pensado, en la desgracia, la injusticia y lo perecedero, sólo así es posible constituir unas novedosas categorías metafísicas.

En Después de Auschwitz Adorno analiza que las categorías tradicionales de la metafísica (o de la filosofía) ofrecieron un modelo de pensamiento que justificaba, sustentaba, obviaba y se hacía cómplice de la barbarie. Por ello, preguntar si aún es posible la filosofía después de Auschwitz implica buscar rutas para romper con dicha co-existencia y que la filosofía asuma su condición por antonomasia: la crítica. Al respecto Adorno (1975) afirma: "Después de Auschwitz, la sensibilidad no puede menos de ver en toda afirmación de la positividad de la existencia una charlatanería, una injusticia para con las víctimas, y tiene que revelarse contra la extradición de un sentido, por abstracto que sea, de aquel trágico destino" (p. 361). 
La sensibilidad es una categoría que, después de Auschwitz, ha de ser tenida en cuenta por la metafísica. Lo tangible, lo corpóreo, en la experiencia humana se rastrea un fundamento para la legitimidad y validez de la metafísica. Sólo de este modo podrá reconstruirse lo que Auschwitz destruyó: la subjetividad, y junto a esta, el desconocimiento de su historia y experiencia. Después de Auschwitz no hay posibilidad para mantener una concepción gnoseológica del sujeto, porque lo ocurrido rompe con cualquier pretensión de sentido al modo idealista. Se rescata al sujeto empírico, al ser humano dentro de la existencia fáctica, al individuo transitorio que experimenta el sufrimiento, el dolor y la tragedia de modo particular e individual.

La muerte, como experiencia genuina del sujeto, después de Auschwitz requiere un tratamiento distinto del que la metafísica le dio en su forma tradicional. La oportunidad de pensar categorías como la muerte y la existencia no ha sido posible porque sencillamente no existe un sujeto al cual se pueda hacer referencia. En esta doble negación ha sido posible constatar la desnaturalización de la muerte y, por qué no, de toda experiencia como signo de existencia. De allí que Adorno exprese: "En los campos de concentración la muerte ha alcanzado un nuevo horror: desde Auschwitz, temer la muerte significa temer algo peor que la muerte" (Adorno, 1975, p. 371). Si la muerte ha sido negada como experiencia, entonces después de Auschwitz una metafísica de la muerte debe resignificarse para que no sea comprendida como un hecho independiente de la condición humana.

\section{Novedosa manera de ver la metafísica: la realidad se expresa en la negación, no en la afirmación}

La novedad de la propuesta de Adorno se direcciona en sentido contrario al sistema propuesto por Hegel. Por esta razón, Honneth (2009) refiriéndose a la "Introducción" de la obra Dialéctica Negativa afirma:

\footnotetext{
... el sistema hegeliano constituye el punto culminante y a la vez de inflexión de la historia de la teorización filosófica, porque por un lado representó la forma más audaz y clara de su pretensión inmanente de penetrar toda la realidad en términos conceptuales, pero por otro lado fracasó de un modo tan dramático que todos los enfoques posteriores deben entenderse como salidas de la "crisis del idealismo". Si se juntan los numerosos excursos sobre historia de la filosofía de la "Introducción", en conjunto dan como resultado exactamente esa imagen de un movimiento que vira en el punto del fracaso de Hegel y que ahora, en lugar de ir hacia un conocimiento cada vez más amplio de la totalidad, va hacia una exploración lo más precisa posible de fenómenos concretos (p. 88).
} 
Adorno considera que Hegel fracasa al entender la realidad fáctica y la experiencia subjetiva como simples sistemas conceptuales. Por ello, en la presentación de Dialéctica Negativa se afirma: "se podría llamar a la Dialéctica Negativa un antisistema... [que] rechaza el principio de unidad y la omnipotencia y superioridad del concepto" (p. 8). En este sentido, "la Dialéctica negativa es una obra que parte de una dialéctica hegeliana invertida" (Barahona, 2006, p. 205). Al respecto Buck-Morss (1981) manifiesta:

... mientras Hegel veía en la negatividad el movimiento del concepto hacia su 'otro', sólo un momento dentro de un proceso mayor hacia la consumación sistemática, Adorno no veía posibilidad alguna de que una argumentación se detuviera en la síntesis inequívoca. Hizo de la negatividad el signo distintivo precisamente porque creía que Hegel se había equivocado: razón y realidad no coincidían (p. 139).

Para el frankfurtiano, la realidad al modo idealista no coincide con expresiones de barbarie como las experimentadas en Auschwitz.

Para Adorno, la definición de la dialéctica parte de la idea de que los objetos, no son reducibles a concepto, porque la realidad escapa al principio de adaequatio, propio de la propuesta hegeliana, ofreciendo un nuevo escenario de análisis en lo que no es conceptualizable. También el concepto debe comprenderse en otro sentido. "La verdad es que todos los conceptos, incluidos los filosóficos, tienen su origen en lo que no es conceptual, ya que son a su vez parte de la realidad" (Adorno, 1975, p. 20).

Con el aforismo Después de Auschwitz, Adorno inicia las Meditaciones sobre la metafisica afirmando: "Si la capacidad de la metafísica ha quedado paralizada, es porque lo ocurrido le deshizo al pensamiento metafísico especulativo la base de su compatibilidad con la experiencia" (Adorno, 1975, p. 362). Con esta tesis se estima que la metafísica construida desde el idealismo, solo puede ser válida en la medida que resuelva y evite acontecimientos como Auschwitz.

La novedad de esta propuesta, frente al idealismo tradicional, Barahona (2006) la aclara concretamente de la siguiente forma: "La dialéctica de Hegel postulaba la identidad entre espíritu y naturaleza, entre razón y realidad, justificando, por tanto, la sociedad y la historia como un proceso absolutamente racional, ajustado a la razón" (p. 205). En este sentido, toda forma de barbarie experimentada en la historia se justifica desde la racionalidad. La coincidencia entre la realidad y la razón desde el principio de identidad, constituye un mundo bajo el dominio del pensamiento. Sin embargo, el asesinato administrativo experimentado en Auschwitz es el signo 
de la incompatibilidad del pensamiento metafísico con la experiencia. Nada puede justificar la capacidad de destrucción de una racionalidad con arreglo a fines. Por esta razón, la novedad de esta idea de metafísica consiste en que el pensamiento debe estar entrelazado con la realidad fáctica, de lo contrario se anula a sí mismo.

Desde el punto de vista epistemológico, según Barahona, "La crítica al pensamiento identificador es quizás el tema clave de la 'dialéctica negativa"' (2006, p. 207). Para Adorno, el principio de identidad marca una forma positiva-científica para entender la relación sujeto-objeto que se desplaza hacia las relaciones del sujeto con la naturaleza. En este sentido, Adorno considera que entre idealismo y metafísica no se atribuyó importancia al papel del objeto respecto al pensamiento. El objeto está a disposición para ser dominado, de manera conceptual, por la racionalidad. Sin duda alguna, este aporte de Hegel es importante para la construcción de la metafísica moderna. Sin embargo, determina una relación donde el objeto, realidad que no es sujeto, bajo el principio de identidad, está totalmente reducido a sustrato de dominio. De allí que se afirme:

En cuento dialéctica idealista, se encontraba remachada con el predominio del Sujeto absoluto y éste era la fuerza que operaba negativamente tanto cada uno de los movimientos del concepto como su proceso de conjunto. La historia ha condenado un tal predominio del sujeto, incluida la concepción hegeliana (Adorno, 1975, p. 15).

Después de Auschwitz, para Adorno, la metafísica rastrea al objeto más allá de su categorización conceptual con base en la cosificación. Considera que, más bien, debe establecerse que el sujeto y el objeto hacen parte de la misma realidad en la idea de la verdad; allí se reconocen, dejan de ser indiferentes entre sí como pretendieron los sistemas idealistas. Por esta razón, Honneth (2009) afirma:

... del giro negativo de la dialéctica Adorno no sólo saca conclusiones sobre la relación con el objeto, sino también en cuanto al sujeto cognoscente... el sujeto, que ya no cree poder apropiarse conceptualmente del mundo, se sabrá por el contrario codeterminado por éste y por lo tanto deberá perder una parte de la soberanía que se le atribuía hasta ahora. Adorno encuentra... que con el giro hacia la dialéctica negativa el sujeto pierde su capacidad de asignación autónoma de sentido; en lugar de eso, dado que siempre tiene que presuponer una porción de realidad no comprendida, debe tomar "conciencia de sí como a su vez mediado". Por eso... el sujeto ya no puede concebirse como centro de la realidad en el sentido de su constitución conceptual (p. 94).

En este sentido, la relación sujeto-objeto toma un giro marcado por el carácter negativo de la dialéctica. Ambos pierden su estructura fija y originaria dada de antemano para complementarse. De este modo, la dialéctica negativa renuncia a 
la identificación entre sujeto y objeto. Por ello, la reflexión filosófica desarrolla lo más relevante que reflejan las categorías sujeto-objeto, a saber, la imposibilidad y el absurdo de pretender reducir todo objeto a objeto pensado. El respeto por lo otro, por lo no idéntico, el reconocimiento de lo diferente, la otredad, confirman que ambos se auto-constituyen (Cf. Brull, 2007, pp. 47-48).

Reconocer el papel del objeto como instancia inefable frente al pensamiento es la manera adecuada para pensar una posible transformación de la realidad. En la prioridad del objeto, la dialéctica se constituye en materialismo. Por esta razón, Adorno (1975) expresa: "La marcha de la historia no deja otra salida que el materialismo a lo que tradicionalmente fue su inmediata oposición, la metafísica" (p. 365).

Según Jameson (2010), ha sido Hitler quien volvió materialista la metafísica y quien incluyó el cuerpo mortal de una manera irrevocable dentro de cualquier especulación de esa índole. En este sentido, el desplazamiento de la metafísica hacia el materialismo no es el resultado de la reflexión teórica, sino de lo que Auschwitz, en cuanto experiencia, revocó de la noción idealista de la metafísica. ${ }^{3}$

No se trata de positivizar la metafísica porque, según Adorno, el positivismo es negación de la metafísica ( $C f$. 1975, p. 400). Con el positivismo, la trascendencia queda anulada porque las realidades que tienen carácter positivo solo tienen propiedades de sensibilidad. En efecto, toda trascendencia, al carecer de esta realidad material, es desechada. De esta manera, la posibilidad resultante es lo no idéntico, lo diferente.

3 De acuerdo con Jarvis (2006), nos hemos acostumbrado a pensar el materialismo como un nombre para referirse a la desmitificación. El materialismo se entiende como pensamiento que libera de creencias engañosas, entidades inmateriales o concepciones ideológicas de la sociedad. Solo importa afirmar que las necesidades materiales son reales, lo que está más allá de ellas es metafísico, idealista o ideológico. Sin embargo, en la práctica la tarea de deshacerse de las ilusiones ha resultado ser mucho más difícil que las observaciones anteriores. En el materialismo se encuentra que era difícil mantenerlo de pie fuera de las ilusiones que se desean disipar. Algo parecido a esta dificultad se puede ver directamente en los orígenes de la tradición que llegó a ser llamada "materialismo". Se supone, por ejemplo, que el materialismo no debe considerarse como una teoría metafísica de lo real, sino, más bien, como un "método". Un método es lo mismo en cuanto procedimiento para investigar diferentes tipos de material. Si el método sigue siendo el mismo para investigar, difícilmente puede ser materialista en absoluto, pues no se verá afectado por los cambios en los objetos que se va a considerar. En este sentido, el materialismo al parecer sigue girando en su contrario, en solo lo que se suponía no ser. En esto ha consistido su carácter idealista. 
Ahora bien, la negación de la metafísica muestra que lo trascendente se sumerge en la totalidad abstracta, característica del sujeto absoluto. La experiencia que no desemboca en la trascendencia se orienta a una constitución del mundo que erradica el sufrimiento establecido y, a su vez, es revocado el que ha sido provocado irrevocablemente ( $C f$. Adorno, 1975, p. 401). Lo existente está cargado con las promesas constantemente rotas de ese otro. "Toda felicidad es fragmento de la felicidad total, que se niega ella misma a los hombres y que éstos se niegan a sí mismos" (Adorno, 1975, p. 401). El sufrimiento como experiencia particular no es conceptualizable, ni puede ser obviado por la totalidad. Por esta razón, Adorno afirma: "La convergencia de todos los pensamiento en el concepto de algo distinto del ente inefable, del mundo" (p. 401). De esta forma, la convergencia sería una experiencia correctiva que encuentra en lo no idéntico una posibilidad. Por ello, discrepa del intento de conmensurabilidad de la idea de trascendencia con la ciencia.

Otra expresión del idealismo ha sido la tendencia a considerar las categorías metafísicas desde la trascendencia como escenario idóneo para imponerse sobre la realidad material. La vida con sentido y la metafisica de la muerte son categorías que no están sujetas a realidades trascendentes, sin embargo, han buscado siempre generar expectativas sobre realidades que están más allá de la vida. De allí que Adorno (1975) exprese: "Las categorías metafísicas perviven secularizadas en la pregunta por el sentido de la vida" (p. 376). El escenario de partida de la reflexión es "la tragedia de la realidad". Esto remite a la pregunta por el sentido de un pensamiento objetivo. No puede haber carácter subjetivo en la respuesta por la pregunta por el sentido; este necesariamente exige la objetividad, porque la vida del sujeto también es la expresión de las vivencias de la colectividad. Negarlo del modo que lo hace la visión idealista, "significa en efecto la proclamación como Absoluto de un Espíritu que, no pudiendo desprenderse de su origen en el deficiente sujeto, sacia su necesidad en su viva imagen. Mientras la metafísica no reflexione la tragedia de la realidad y la pregunta por el sentido, toda pretensión por hacerlo queda anulada" (p. 376).

En suma, las categorías metafísicas no pueden estar basadas en ideologías al modo hegeliano, sino en la experiencia que no trasciende la realidad del sujeto. Experiencias como el sufrimiento humano, no permiten ser caracterizados ni representados por una explicación racional (Cf. Zamora, 2010, p. 184). 
En Perfiles filosóficos-políticos, Habermas (1975) ratifica esta connotación de la objetividad en términos adornianos:

\begin{abstract}
Objetividad designa, en primer lugar, el carácter coactivo de una trama histórica universal que se encuentra bajo la causalidad del destino... lo objetivo significa también el sufrimiento bajo aquello que pesa sobre los sujetos. El conocimiento de la trama objetiva nace, por tanto, del interés de apartar ese dolor. La expresión significa además la objetividad sobre toda subjetividad que se pone fuera de ella (p. 157).
\end{abstract}

En este sentido, es importante reconocer el papel de la colectividad y la historia para ser reconocidas como categorías de una nueva idea de filosofía después de Auschwitz. El sujeto se sabe individuo en medio de una sociedad compuesta por individualidades, que son necesarias para la interacción, y buscan cumplir una función importante en la formación de la subjetividad.

Finalmente, Dialéctica Negativa intenta mostrar que la expectativa del principio de identidad, baluarte del sistema hegeliano, se desplace hacia el objeto no idéntico y pueda establecer una reconciliación con lo diferente, lo que no es idéntico. Concretamente se afirma:

el fin de la dialéctica sería la reconciliación. Esta emanciparía lo que no es idéntico, lo rescataría de la coacción espiritualizada, señalaría por primera vez una pluralidad de lo distinto sobre la que la dialéctica ya no tiene poder alguno (Adorno, 1975, p. 15).

Para Adorno, no es posible afirmar sin más que el principio de identidad "es un pecado capital" (Adorno, 1975, p. 404), porque el principio de identidad es necesario para que haya conocimiento. Sin embargo, se trata de replantear ese proceso que se hipostasió como dominación y anulación de lo real. El hecho de que "la metafísica emigre a la Micrología" (Adorno, 1975, p. 404) es la explicación de su posibilidad en aquello que escapa al principio de identidad. La metafísica no puede estar dentro de un sistema gnoseológico en el que se reduzca la realidad a un plano netamente epistemológico. La experiencia del sujeto marca una posibilidad en aquello que está más allá de lo que el conocimiento pueda expresar de él.

En este sentido, la metafísica direccionada hacia lo diferente, lo particular, lo que no es posible a través del principio de identidad, posibilita tener esperanza desde una dialéctica de la negatividad. Por esta razón, Adorno considera que la metafísica "debe ser experta en deseos... [Porque] también el pensamiento es una conducta y encierra en sí la necesidad de algo, comenzando por la premura 
de la vida" (Adorno, 1975, p. 405). El pensamiento como acción requiere de una necesidad que es dependiente de la acción en el marco de una metafísica de lo desamparadamente particular.

De esta manera, la tarea de la dialéctica es "destruir la existencia de identidad" (Adorno, 1975, p. 403) que solo ve en la realidad objetiva una posibilidad para el espíritu. Por esta razón, la metafísica en el nuevo escenario de la negatividad y apartada de los argumentos hegelianos, rescata la realidad de la conceptualización $\mathrm{y}$ anula el principio de identidad, para encontrar un escenario en el cual lo real recobra sentido para poder ser pensado de una forma nueva y distinta.

\section{De la idea de trascendencia en Kant a la idea de emancipación en Adorno}

Para Adorno, pensar en una idea de filosofía después de Auschwitz solo es posible en el momento de su caída. Ese instante de venirse abajo es, según Wellmer (1996), "la etapa última de la Ilustración europea desde Kant, y entendida en un sentido estrecho el crimen de Auschwitz como instante de la consumación y autoborradura de esa ilustración" (p. 220). Por esta razón, el frankfurtiano parte de categorías kantianas sobre la metafísica para lograr establecer un diálogo con ellas y, a partir de allí, saber si todavía existe la posibilidad de la idea de metafísica después de Auschwitz. Por ello, en el aforismo Morir hoy Adorno (1975) afirma:

La cuestión que establece la filosofía de la historia, de si la experiencia metafísica es todavía meramente posible, sustituye el planteamiento gnoseológico de Kant sobre cómo es posible la metafísica... Las ideas metafísicas se hallaban en Kant exenta de los juicios de existencia con que la experiencia requiere su material (p. 372).

Lo importante para Adorno no es resolver el cómo, sino responder si aún es posible la filosofía, es decir, el qué, en medio de una existencia desgarrada.

En principio, para el autor de la Crítica de la razón pura, según Adorno, los acontecimientos históricos no constituyen un aporte a la reflexión epistemológica en su teoría del conocimiento. ${ }^{4}$ Por esta razón, la crítica que hace a las estructuras

4 Según Buck-Morss (1981), es importante comprender que el impulso de Adorno sobre la filosofía de la historia no nace de sus reflexiones sobre Kant o Husserl, considerados pensadores ahistóricos, sino que fueron sus estudios musicales los que despertaron su conciencia de la significación vital de la dimensión histórica. La música, que muchas veces ha sido considerada como la expresión abstracta de 
kantianas sobre el conocimiento limitado y a la metafísica está dirigida a la experiencia que ha marcado a la conciencia en el escenario reflexivo-teórico, y ello conllevó a que la razón práctica se haya establecido con base en las ideas metafísicas en la forma de ideas regulativas, lo cual trajo como consecuencia que se haya olvidado el contexto donde el sujeto se encuentra determinado. Para Kant, toda relación entre metafísica y realidad está dentro de los límites del conocimiento científico o metafísico. De allí que

La crítica de Adorno se endereza contra el trazado de límites que Kant establece entre el ámbito de lo empírico y el ámbito de los inteligible, que es la condición de la salvación crítica que Kant efectúa de la metafísica (Wellmer, 1996, p. 221).

Según Adorno, no se puede negar la importancia de la tarea reflexiva realizada por Kant. Por ello, reconoce que "La aportación fundamental de la Crítica de la razón pura [ha sido] la concluyente separación entre el conocimiento válido y metafísica" (Adorno, 1975, p. 381). Más allá de su contenido gnoseológico, la Crítica de la razón pura "marcó el nivel de experiencia alcanzado por la conciencia" (Adorno, 1975, p. 381). En efecto, bajo estos presupuestos, existe una realidad objetiva de carácter material que viabiliza el conocimiento, su validez y el límite de la experiencia; y existe una realidad que puede ser reflexionada y pensada por ideas que son indeterminadas para la sensibilidad. En este sentido, según la perspectiva kantiana, las ideas o realidades metafísicas no tienen posibilidades de realidad objetiva porque no permiten atribuirle posibilidad de experiencia. Sin embargo, según Wellmer (1996), “Adorno muestra en cambio que, como meros pensamientos (las ideas trascendentales), serían vacías si no pudiesen ser pensadas en la perspectiva de una experiencia posible, es decir, sub especie de una realidad objetiva por lo menos posible" (p. 221).

En este sentido, para Adorno la esfera de lo inteligible en Kant presenta ciertas ambigüedades aún sin resolver. Por un lado, no ha sido posible comprender cómo las ideas de Dios, libertad e inmortalidad tienen que ser pensadas como reales, aunque no sean cognoscibles. Por otro parte, no se entiende cómo estas ideas del plano de lo trascendente sean ideas posibles de ser alcanzadas por la finitud de la racionalidad del sujeto, cuya racionalidad es destinada y limitada por el conocimiento científico.

las artes, es en el sentido histórico la más concreta, ya que ningún arte está más integralmente referido a la dimensión temporal. 
Para el autor de Dialéctica Negativa, la estructura del sistema kantiano monopolizó ilegítimamente la verdad. Por ello, lo que pasa en la noción de conocimiento de Kant si se compara con la experiencia de los hombres reales queda limitada. Según Brull (2007), no solo Kant, sino también la crítica posterior del idealismo, pasaron por alto que el sujeto gnoseológico es un sujeto abstraído del hombre vivo particular. De este modo, la reflexión epistemológica debe girar hacia la teoría social, tal como lo hizo Adorno. Por ello, Wellmer (1996) manifiesta:

Es el curso de la historia el que obliga a la metafísica al materialismo, contra el cual
venía inicialmente concebida; la obliga a descender a ese «escenario del dolor», a ese
«estrato o nivel somático del viviente, que resulta lejano al sentido», tras que en los
campos de concentración «se quemara sin remedio todo elemento tranquilizador del
espíritu» (p. 225).

Según lo anterior, la metafísica es parte constitutiva de la realidad y no de la racionalidad pura. La historia es el escenario de las categorías metafísicas que sirven de argumento para sostener una esperanza en la redención concebida en términos materialistas ( $C f$. Wellmer, 1996, p. 227). Es decir, es una esperanza en la redención que busca la transformación de la realidad no mediante mesianismos religiosos, sino de la transfiguración de la realidad histórica. No hay una historia superada por la metafísica; al contrario, es un nuevo estado desde sí misma. De este modo, la esperanza en la redención dentro del escenario histórico es la confirmación de la esperanza en una vida realizada.

Para Kant, la relación entre las categorías de forma y contenido determinan el conocimiento válido. Sin embargo, Adorno (1975) considera que según esta tesis "La conciencia humana... se halla condenada como a prisión perpetua en las formas del conocimiento tal y como le han sido dadas" (p. 385). El sujeto se encuentra determinado como simple apercepción originaria del que parte toda posibilidad de conocimiento científico. El contenido real "lo que les afecta [a las formas], carece de toda determinación y sólo la recibe de las formas de la conciencia" (Adorno, 1975, p. 385). En efecto, el contenido real solo cumple con el dinamismo para el conocimiento científico de ser percibido por la formas sin afectar, de modo alguno, al sujeto. Por esta razón, la realidad externa al sujeto se reduce a material perceptible con un solo propósito: ser percibido.

Otra consecuencia es la imposibilidad de predecir el futuro porque en la mediación entre la forma y el contenido existe una limitación temporal que no es 
posible descifrar. La realidad queda instituida y reducida a lo dado y percibido, lo que imposibilita la manifestación de lo concreto en un camino donde solo es posible el conocimiento científico.

Por otra parte, existe una sospecha social de que el bloque kantiano es igual a la miseria del trabajo que mantiene a los hombres en el hechizo que Kant transfiguró en filosofía; así como en la prisión de la inmanencia se encuentra el espíritu, de la misma manera se halla la autoconservación en esa prisión. La limitación del conocimiento ha confirmado la prisión en la cual se encuentra el sujeto en las condiciones sociales actuales. La conciencia está determinada por la objetividad, de tal manera que la separación entre sensibilidad y entendimiento, el nervio de demostración del bloque, es a su vez producto social (Cf. Adorno, 1975, p. 388). Si se llegara a romper la limitación de la experiencia respecto a las condiciones que hacen posible la ciencia, habría espacio para la comprensión de que el hombre es mucho más que aquello que lo aprisiona en sí mismo; es decir, habría otro espacio para no limitar la idea de sujeto a la reducción de un sujeto gnoseológico. El hecho de que Kant elevara la subjetividad a estructura formal, terminó eliminando todo rastro de auténtica espontaneidad, y convirtió la subjetividad en objetividad sin rastros de sujeto ( $C f$. Brull, 2007, p. 48). Por ello, Adorno (1975) considera que "La doctrina kantiana... a pesar de construir un pedazo de la apariencia social, se halla fundada, sin embargo, tal y como la apariencia domina de hecho a los hombres" (p. 388).

Según Adorno, si existe algo que explique mejor la imposibilidad de comparar el conocimiento con la experiencia de los hombres históricamente específicos es la estructura del mundo construido por el entendimiento; pero ello, no configura un escenario para que la sensibilidad se haga presente con aquellos que han sido victimizados ( $C f$. Adorno, 1975, p. 388). Es decir, la estructura del mundo y su dinámica solo responde a una posibilidad del conocimiento, cuyo fundamento radica en la sensibilidad. Ésta representa más de lo que la estructura del entendimiento hace de ella. Por eso, la experiencia de los seres humanos específicos no es comparable con la limitación del conocimiento.

En Kant, las ideas metafísicas son realidades regulativas y su "materialización" no depende de vinculaciones realizadas por el pensamiento con determinados objetos. La posibilidad de pensar es una cuestión de la cual no es deducible una conexión con la realidad material. Por ello, Adorno (1975) afirma: "la aversión 
desesperada de Kant por la ilusión de que el postulado sea un juicio de existencia, ha sido después evitada penosamente" (p. 389). De hecho, bajo la idea de presunción teórica Kant no acepta que el postulado [II B 479] (Cf. Kant, 1997, p. 471) sea un juicio de existencia. En este sentido, pensar la libertad por fuera de las facultades de la razón pura implica que sea otra facultad la que pueda pensarla. Por ello, "la presunción audaz" supone una facultad pensada pero no experimentable. La imposibilidad de su correlación con la realidad objetiva supone una instancia por fuera de las estructura de la razón y que, en palabras de Adorno (1975), se conoce como una "presunción teórica" (p. 389).

Por otro lado, la Crítica de la razón práctica se orienta a una positividad del mundo inteligible. Una razón infinita supone la posibilidad de concederles materialidad a las ideas metafísicas y que no habría límite para conseguirlo. Adorno (1975) manifiesta: "En efecto, estas expresiones no se refieren a una mera posibilidad de comportamiento, sino que son por definición postulados de algo existente, sea cual sea su constitución" (p. 390). Las ideas no pueden ser tangibles, ni espejismos del pensamiento, pues perderían su objetividad. La categoría de lo inteligible "no se refiere ni a algo real ni a algo imaginario, sino que es una aporía" (Adorno, 1975, p. 390). Desde esta perspectiva se podría afirmar que la forma kantiana de la metafísica cumple con esa definición de lo inteligible aportadas por Adorno. De este modo, inmediatamente queda separada de esta nueva concepción. La preocupación por asirlo, establecerlo, determinarlo no es más que el movimiento, la desestabilización que provoca la autoconservación — ganar seguridad, estabilidad, en lo ya establecido- que reacciona ante el argumento crítico. En Kant, lo inteligible goza de una autoridad absoluta que es independiente de la realidad objetiva y mantiene, en perspectiva adorniana, un "carácter de una segunda existencia" (Adorno, 1975, p. 390).

La posibilidad para la metafísica se basa en que el espíritu participe de la realidad. Sin embargo, aunque Kant haya señalado la imposibilidad de la teoría sin la metafísica, la salvación de la esfera inteligible no está ahí, pues el ámbito en el cual se especifica la metafísica es en el de lo teórico. Pero el "que la teoría sea posible implica ese derecho de la filosofía al que se atuvo el mismo Kant, que la deshacía como resultado de su obra" (Adorno, 1975, p. 384). Salvar lo inteligible en la realidad histórica concreta permite a la metafísica salir de lo meramente conceptual para intentar intervenir en la realidad objetiva. Su pureza trascendental y su objetividad trascendente no pueden estar separadas como categorías independientes 
de la realidad objetiva ( $C f$. Adorno, 1975, pp. 391-392). El ámbito de lo inteligible es el de algo que no es y no solamente no es. Aquí la verdad es frágil. El espacio de lo real concreto, que niega aquello que no es propio de su ámbito, es decir, lo inteligible, "debería ser rechazado sin resistencia como imaginario" (Adorno, 1975, p. 392). Esta realidad adolece de presunciones para sostener la verdad de sus propias nociones. El pensamiento podría tratar de sustantivar, de otorgar un nombre para intentar poseer lo que perdió. La negación de la negación no se constituye en afirmación; por eso, la denominación de Kant a la dialéctica trascendental es "una lógica de la apariencia".

Finalmente, a juicio de Adorno, los aportes hechos por Kant en sus tratados sobre la razón han sido la base gnoseológica para organizar, limitar y estructurar un mundo epistemológicamente divido. De allí que, igualmente, sus postulados morales quedan totalmente en entre dicho si los juicios de la razón son reflexionados desde un acontecimiento categórico como Auschwitz. La trascendencia asumida por la facticidad de Auschwitz niega cualquier idealización del pensamiento y las acciones de los hombres. Por ello, el imperativo categórico en la formulación adorniana se convierte en el centro de la reflexión de la posibilidad de una idea de filosofía después de Auschwitz. Posibilidad que comprende la trascendencia no en una esfera de un inteligible separado de la realidad, sino, más bien, unido a ella. Por esta razón, Adorno al expresar un nuevo horizonte de sentido para la moral que busca la no repetición de Auschwitz da un giro importante a la teoría y la praxis. De allí que se afirme: "No hay más que una forma de iniciar la resistencia... comenzar modestamente por la praxis" (Adorno, 1975, p. 342). La praxis, unida al pensamiento, impone una nueva perspectiva ética alrededor de una idea de filosofía que tiene como referencia la no repetición de Auschwitz.

\section{Conclusión}

Dialéctica Negativa, obra cumbre de Adorno, expone las categorías de su pensamiento, y con base en ello presenta una novedosa manera de estudiar y comprender las categorías de los diferentes sistemas de la razón que terminaron siendo entendidos como fracasados después de la concretización de una expresión de la barbarie como Auschwitz. El culmen de su propuesta fue el planteamiento de un nuevo horizonte de sentido que se constituye en el objeto de estudio para la filosofía. Se trata de la realidad fáctica e histórica de los seres humanos. El problema 
del pensamiento tradicional consistió en haber quedado inmerso en una metafísica que, al asumir un carácter trascendental, discrepa de la realidad y como consecuencia se idealiza. En la facticidad, la historia, los testimonios, la narración que deviene de Auschwitz, aparece un horizonte novedoso de sentido para la filosofía.

En Dialéctica Negativa Adorno hace una reflexión epistemológica de la tradición de la Ilustración en sus principales representantes: Kant y Hegel. La afirmación categórica de la relación de la barbarie con el principio de identidad le lleva a pensar los problemas de las categorías metafísicas que han servido de base para estos sistemas de pensamiento. Por un lado, la discusión con Hegel alrededor del problema de la historia y la constitución del Espíritu Absoluto como los fundamentos más notorios de su trabajo filosófico, llevan a Adorno a rechazar cualquier sentido histórico que justifique los sufrimientos y atrocidades vividos en Auschwitz.

Frente a la construcción gnoseológica de Hegel que entiende la relación sujeto-objeto bajo el principio de identidad, el frankfurtiano considera que ha sido este tipo de constitución epistémica la que ha posibilitado el entrelazamiento entre racionalidad y barbarie. Una racionalidad que aprehende al objeto solamente como objeto identificado, luego conceptualizado, permite entender la realidad como sustrato de dominio de la cual el sujeto, desde la racionalidad, puede hacer uso. Para el autor de Dialéctica Negativa la realidad no es posible reducirla a concepto. La dificultad es mayor con realidades que escapan a la reflexión epistemológica. Precisamente, la experiencia humana manifestada en la tragedia del terror, debe ser tenida en cuenta en la reflexión de una nueva idea de filosofía. Frente a Auschwitz, como expresión metafórica de la barbarie, no solo se pone en duda la sociedad idealizada por la racionalidad, sino que se fija un nuevo compromiso de la filosofía para evitar nuevas formas de barbarie.

Por otro lado, en Kant su dualismo racionalista, aun cuando intenta llegar a intervenir en la realidad, el sujeto neutraliza todo aquello que es externo a sí mismo. Lo trascendente en Kant pasa por una idealización de los juicios puros de la razón creyendo poder hacer de la realidad un objeto para la aprehensión del sujeto. Adorno discrepa de Kant al anular cualquier subjetivismo gnoseológico y la reducción de la realidad a sustrato de conocimiento. Las reflexiones epistemológicas después de Auschwitz se concretan en la realidad, sus circunstancias, situaciones, problemas y oportunidades. Kant creyó demasiado en la razón y redujo la realidad a escenario 
para la concreción de sus proyectos. Por el contrario, Adorno piensa que si hay una posibilidad para el pensamiento, ésta radica en no perder de vista que, la realidad en la que el sujeto se encuentra inmerso, es un buen principio para poder reflexionar y generar proyectos humanos más reales. El sufrimiento, la experiencia concreta e individual del sujeto, la muerte, se convierten en categorías a tener en cuenta para una nueva idea de filosofía.

Finalmente, Hegel y Kant, según Adorno, fracasan en sus sistemas de pensamiento al comprender la realidad y el sujeto en un escenario epistemológico incapaz de explicar situaciones de dolor como los experimentados en Auschwitz. De esta manera, el frankfurtiano ofrece una nueva idea de filosofía para evitar la repetición de la barbarie y que el hechizo que la entrelaza con la racionalidad se rompa. Ahora la filosofía se torna en metafísica negativa, porque se dirige y concentra en lo que ha sido rechazado por los sistemas idealistas en la modernidad. La negatividad se perfila no solo como una crítica a lo existente, sino en la única posibilidad que tiene la filosofía para constituirse como una verdadera metafísica de la reconciliación.

\section{Referencias}

Adorno, Th. (1975). Dialéctica Negativa (J. M. Ripalda, Trad.). Madrid: Taurus.

Barahona, E. (2006). Categorías y modelos en la Dialéctica Negativa de Th. W. Adorno: crítica al pensamiento idéntico. Logos. Anales del Seminario de Metafísica, 39, 203-233.

Buck-Morss, S. (1981). Origen de la Dialéctica Negativa: Theodor W. Adorno, Walter Benjamin y el Instituto de Frankfurt. Bogotá: Siglo veintiuno.

Brull, R. (2007). La Dialéctica Negativa en Adorno: aplicación a la teoría social (Tesis de Doctorado para optar al título de Doctor en Filosofía). Facultad de Filosofía Universitat de Valencia, Valencia, España.

Cho, D. (2009). Adorno on Education or, Can Critical Self-Reflection Prevent the Next Auschwitz? Historical Materialism, 17, 74-97.

Escuela, C. (2007). El esfuerzo de Munchhausen: Dialéctica adorniana del concepto. En M. Cabot (Ed.), El pensamiento de Th. W. Adorno: balance y perspectiva (pp. 97-103). Palma: Ediciones UIB.

Habermas. J. (1975). Perfiles filosóficos-políticos (M. Gimenez, Trad.). Madrid: Taurus.

Honneth, A. (2009). Patologías de la razón. Historia y actualidad de la Teoría Crítica (G. Márcico, Ttrad.). Buenos Aires: Katz Editores. 
Jameson, F. (2010). Marxismo tardío: Adorno y la persistencia de la dialéctica (M. de Ruschi, Trad.). Buenos Aires: Fondo de cultura económica.

Jarvis, S. (2006). Adorno, Marx, Materialism. En Tom Huhn (Ed.), the Cambridge Companion to Adorno (pp. 79-100). Cambridge: Cambridge University Press.

Kant, E. (1997). Crítica de la razón pura (P. Ribas, Trad.). Buenos Aires: Santillana.

Peleato, M. (2007). Dialéctica de la Identidad: De la identificación a la identidad racional. En M. Cabot (Ed.), El pensamiento de Th. W. Adorno: balance y perspectiva (pp. 87-95). Palma: Ediciones UIB.

Teimil, I. (2007). Emancipación y potencial constructivo del concepto en la Dialéctica Negativa de Adorno. En M. Cabot (Ed.), El pensamiento de Th. W. Adorno: balance y perspectiva (pp. 79-86). Palma: Ediciones UIB.

Wellmer, A. (1996). Finales de partida: la modernidad irreconciliable (M. Jiménez, Trad.). Madrid: Frónesis.

Zamora, J. (2010). Filosofía después de Auschwitz. En O. Nudfer (Ed.), Filosofía de la filosofía (pp. 173-213). Madrid: Trotta. 